\title{
openheart Risk factors and a 3-month risk score for predicting pacemaker implantation in patients with atrial fibrillation
}

\author{
Frederik Dalgaard (10 , , Jannik Langtved Pallisgaard, ${ }^{1}$ Tommi Bo Lindhardt, ${ }^{1}$ \\ Gunnar Gislason, ${ }^{1}$ Paul Blanche, ${ }^{1}$ Christian Torp-Pedersen, ${ }^{2}$ Martin H Ruwald ${ }^{1}$
}

\begin{abstract}
- Additional material is published online only. To view please visit the journal online (http://dx.doi.org/10.1136/ openhrt-2019-001125).
\end{abstract}

To cite: Dalgaard F Pallisgaard JL, Lindhardt TB, et al. Risk factors and a 3-month risk score for predicting pacemaker implantation in patients with atrial fibrillation. Open Heart 2020;7:e001125. doi:10.1136/

openhrt-2019-001125

Received 27 June 2019 Revised 19 February 2020 Accepted 25 February 2020
A) Check for updates

\section{(C) Author(s) (or their} employer(s)) 2020. Re-use permitted under CC BY-NC. No commercial re-use. See rights and permissions. Published by BMJ.

${ }^{1}$ Cardiology, Gentofte Hospital, Hellerup, Denmark

${ }^{2}$ Health Science and Technology, Aalborg Universitet, Aalborg, Denmark

\section{Correspondence to}

Frederik Dalgaard;

fdalgaard87@gmail.com

\begin{abstract}
Objectives To identify risk factors and to develop a predictive risk score for pacemaker implantation in patients with atrial fibrillation (AF).

Methods Using Danish nationwide registries, patients with newly diagnosed AF from 2000 to 2014 were identified. Cox proportional-hazards regression computed HRs for risk factors of pacemaker implantation. A logistic regression was used to fit a prediction model for 3-month risk of pacemaker implantation and derived a risk score using $80 \%$ of the data and its predictive accuracy estimated using the remaining $20 \%$.

Results Among 155934 AF patients included, the median age (IQR) was 75 (65-83) and $51.3 \%$ were men. During a median follow-up time of 3.4 (1.2-5.0) years, 8348 (5.4\%) patients received a pacemaker implantation. Risk factors of pacemaker implantation were (in order of highest risk first) age above 60 years, congenital heart disease, heart failure at age under 60 years, prior syncope, valvular AF, hypertension, ischaemic heart disease, male sex and diabetes mellitus. The derived risk score assigns points ranging from 1 to 14 to each of these risk factors. The 3-month risk of pacemaker implantation increased from $0.4 \%$ (95\% Cl: 0.2 to 0.8 ) at 1 point to $2.6 \%(95 \% \mathrm{Cl}$ : 1.9 to 3.6$)$ at 18 points. Area under the receiver operator characteristics curve was 62.9 (95\% Cl: 60.3 to 65.5$)$. Conclusion We highlighted risk factors of pacemaker implantation in newly diagnosed AF patients and created a risk score. The clinical utility of the risk score needs further investigation.
\end{abstract}

\section{INTRODUCTION}

Patients with atrial fibrillation (AF) of all types (paroxysmal, persistent and permanent) have an increased risk of symptomatic bradycardia due to sinus node and atrial remodelling by disease progression and the use of rhythm and rate-lowering drugs. ${ }^{12}$ Bradycardia may lead to excess associated morbidity, traumatic falls and reduced quality of life necessitating a permanent pacemaker (PPM). ${ }^{34}$ Furthermore, AF is a prevalent condition in patients with bradycardia such as sick sinus node syndrome (SSS) and atrioventricular (AV) blocks. ${ }^{15}$ Previous studies have focused on rhythm-lowering or rate-lowering induced

\section{Key questions}

What is already known about this subject?

- In patients with atrial fibrillation, bradycardia may lead to excess associated morbidity and subsequently pacemaker implantation.

What does this study add?

- We found important risk factors of pacemaker implantation in patients with atrial fibrillation and developed a risk score to predict pacemaker implantation in these patients.

How might this impact on clinical practice?

- The risk factors are important knowledge for risk stratification of patient with atrial fibrillation. The clinical utility of the risk score requires further investigation.

symptomatic bradycardia requiring pacing, but research on clinical risk factors for PPM is lacking. ${ }^{6-8} \mathrm{AF}$ patients with a PPM have a high presence of concomitant cardiovascular comorbidities. ${ }^{9}$ We hypothesised that these comorbidities possibly contribute to cardiac conduction disease progression leading to a PPM. By improving risk stratification of AF patients, there is the potential to enhance rhythm monitoring and timing of PPM and reduce bradycardia-related morbidity. The purpose of the study was to identify risk factors for PPM, predict the absolute risk of PPM and to construct and internally validate a risk score to use as a clinical decision tool in a newly diagnosed AF cohort.

\section{METHODS}

A cohort study using the Danish nationwide registers was conducted. At birth or immigration, all Danish residents are provided with a unique and permanent civil registration number enabling cross-linking between nationwide registers on the individual level. The following registers were used to identify patient characteristics, procedures including 
PPM, concomitant pharmacotherapy and comorbidities: The Civil Registration System, The Danish Register of Causes of Death, The Danish National Patient Register and The Danish Register of Medicinal Product Statistics. The Civil Registration System includes data on age, sex and vital status. The Danish National Patient Register has information on date of hospital admissions in Denmark since 1978, date of discharge with one primary diagnosis and one or more secondary diagnoses defined by the International Classification of Diseases the 10th revision (ICD-10) since 1994. Procedures have been registered since 1996 and coded by The Nordic Classification of Surgical Procedures. The Danish Register of Medicinal Product Statistics holds information on drug prescriptions redeemed since 1994. The international anatomical therapeutic (ATC) chemical classifies each drug.

\section{Study population}

The Danish National Patient Register was used to identify patients with a primary or secondary diagnosis of newly diagnosed AF (ICD-10: I48) including both inpatient or outpatients from 1 January 2000 to 31 December 2014. Follow-up stopped on 31 December 2015. In Denmark, some AF patients are exclusively treated in the primary healthcare sector, and thus have an unknown onset of $\mathrm{AF}$ before admitted or referred to an outpatient clinic with an AF diagnosis. To exclude AF patients treated only in primary care, ATC codes were used to identify and exclude patients who had previously been treated with digoxin, antiarrhythmic drugs (amiodarone, dronedarone, class-1c: flecainide, propafenone) and up to 1 year prior treatment of vitamin K-antagonists or nonvitamin $\mathrm{K}$ oral anticoagulants. Patients who had undergone prior cardioversion and ablation procedures for AF were excluded. Patients with prior PPM identified by procedure codes were also excluded.

\section{Outcomes of pacemaker implantation and all-cause mortality}

Procedure codes were used to identify the date of firsttime procedure codes of PPM. The procedure codes have previously been validated. ${ }^{10}$ Date of death was obtained from the Danish Civil Registration system.

\section{Baseline comorbidity, procedures and cardiovascular pharmacotherapy}

Comorbidities at baseline were identified by ICD-10 codes using primary and secondary diagnoses in both inpatient and outpatient, up to 5 years prior to inclusion. Comorbidities were ischaemic heart disease (IHD), heart failure (HF), diabetes mellitus (DM), chronic kidney disease, chronic obstructive pulmonary disease, autoimmune disorders, valvular AF, congenital heart diseases (CHD), hypertension and prior syncope. Diagnosis of bradycardia at baseline was also identified. Procedures were also identified up to 5 years from inclusion. ATC codes were used to identify prescription drugs claimed at pharmacies 180 days prior to the date of inclusion. Antidiabetic drugs were used as a proxy for DM. Hypertension was defined as the use of a combination of at least two of the seven different antihypertensive drugs classes at the same time. All ATC, ICD and procedure codes used are available in online supplementary table 1 .

\section{Statistical analyses}

All patients were followed from date of first-time admission or outpatient visit with an AF diagnosis until date of PPM implantation, death, emigration, 5 years from baseline or end of follow-up (December 2015), whichever came first. Age was categorised into four groups: $\leq 60,61-70,71-80$ and $\geq 81$ years of age. The cumulative incidence functions (ie, risk) of PPM and competing death without PPM within 5 years were estimated using the Aalen-Johansen estimator. Cause-specific Cox proportional-hazards regression analyses were used to estimate adjusted HRs for PPM and all-cause mortality with 95\% CI. Proportional hazard assumptions were assessed graphically by Schoenfeld residual plots. An interaction between HF and age was found and was thus entered into the causespecific Cox models and the prediction model as such. To clarify indications for PPM, type of PPM and bradycardia hospitalisations up to 30 days prior to PPM procedure were identified. Rate-lowering and antiarrhythmic drugs prescriptions claimed up to 3 months prior PPM procedure were identified. AV node ablation procedures were identified 1 month prior to PPM procedure and up to 2 months post PPM procedure.

For the logistic prediction model, to avoid predicting on events during initial AF hospitalisation, the follow-up started from two independent contributing cohorts. Either first-time AF discharge diagnosis or first-time AF at the outpatient visit date-thereby excluding patients who died or received a PPM during first AF hospitalisation. To construct and evaluate the prediction model, the cohort was split into a learning ( $80 \%$ of the data) and a validation cohort (20\%). The learning cohort was used to estimate to what extent each risk factor could independently predict the 3-month risk of PPM; 3 months were chosen because covariates used were not informative enough to make long-term predictions. Covariates were chosen based on availability and a priori knowledge of suspected risk factors of PPM. The covariates chosen were sex, age, hypertension, IHD, DM, HF, syncope and CHD. The prediction model was estimated using a logistic regression adjusted for calendar year. There was no censoring issue as the data did not contain any loss to follow-up within the first 3 months. The points associated with each risk factor were defined by multiplying by 10 and rounding the corresponding parameter. The risk score was defined as the sum of these points. The validation cohort was used to evaluate the performance. Plots of the distribution of risk points and their corresponding 'observed' 3 months risk of PPM illustrate the discriminative performance in the validation cohort. Observed risks, true positive, false positive rates, positive and negative predictive values were computed as empirical proportions and associated CIs were computed using the exact binomial method. 


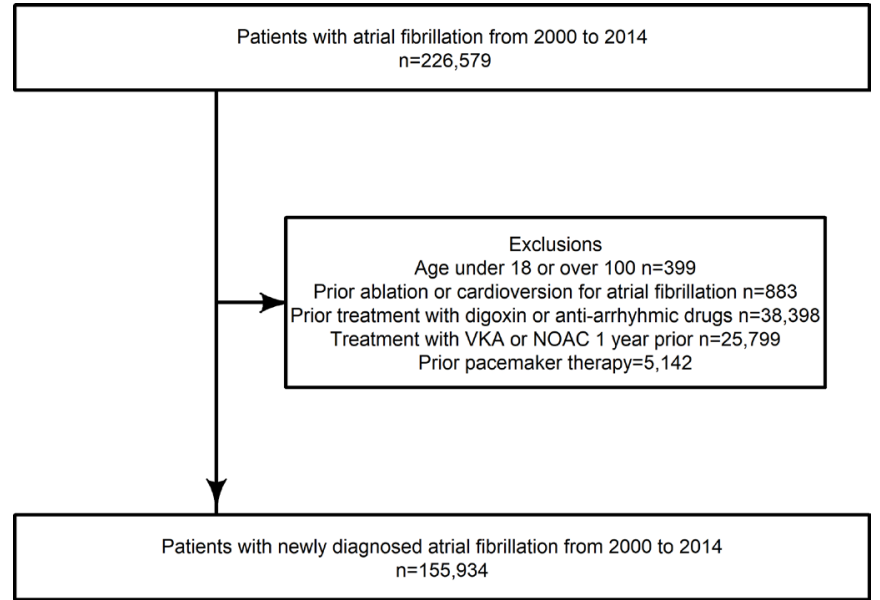

Figure 1 Flowchart of study inclusion. NOAC, non-vitamin $\mathrm{K}$ anticoagulants; VKA, vitamin-K antagonist.

Receiver operator characteristics (ROC) curves and area under the curve (AUC) were also computed, with $95 \%$ CI, for quantifying predictive accuracy of the 3-month and 5-year risk of PPM. We used Delong's method for the 3-month outcome and an appropriate method to handle censored data for the 5-year outcome. ${ }^{11}{ }^{12}$ We repeated the analysis using the entire data for both building and evaluating the risk score. A sensitivity analysis excluding cardiac resynchronisation therapy (CRT) as an outcome was performed in the Cox model to determine if the risk factors remained the same. A two-sided $p$-value $<0.05$ was considered statistically significant. Data management and statistical analyses were conducted using $\mathrm{R}$ statistics (Team RC. R: A Language and Environment for Statistical Computing. Vienna, Austria: R Foundation for Statistical Computing; 2018).

\section{RESULTS}

A total of 155934 patients with newly diagnosed AF were included between 2000 and 2014 (figure 1) with a median follow-up time of 3.4 years $(1.2-5.0)$. Overall median age (IQR) was $75(65-83)$ years, and $51.3 \%(\mathrm{n}=79969)$ were male. Baseline characteristics are shown in table 1. During follow-up, $8348(5.4 \%)$ patients received a PPM implantation (figure 2). At baseline, 1381 (0.9\%) had SSS, and $1605(1.0 \%)$ received a PPM during hospitalisation for first-time AF.

\section{Risk factors}

Several risk factors were independently associated with the rate of PPM implantation. An interaction with HF and age was significant ( $p$-value $<0.001)$ and thus results are shown in table 2 stratified by the presence of HF. The rate of PPM for AF patients with $\mathrm{HF}$ and without $\mathrm{HF}$ increased significantly with age, and age $>80$ years without $\mathrm{HF}$ lead to the largest adjusted risk factor (HR (95\% CI): 4.17 (3.77 to 4.61)). CHD was highly associated with PPM (2.42 (1.74 to 3.38)) and HF was found to be a significant risk factor particularly among AF patients aged $\leq 60$ years (2.34 (1.92 to 2.85$))$. Other important risk factors

\section{Table 1 Baseline characteristics}

\begin{tabular}{|cc|}
\hline & Overall \\
\hline $\mathrm{n}$ & 155934 \\
\hline Sex, male (\%) & $79969(51.3)$ \\
\hline Age (median (IQR)) & $75(65-83)$ \\
\hline Comorbidities, $\mathrm{n}(\%)$ & \\
\hline Ischaemic heart disease & $33114(21.2)$ \\
\hline Heart failure & $26416(17.0)$ \\
\hline Valvular atrial fibrillation & $1896(1.2)$ \\
\hline Congenital heart disease & $409(0.3)$ \\
\hline Chronic obstructive pulmonary disease & $17660(11.3)$ \\
\hline Autoimmune disorders & $1708(1.1)$ \\
\hline Chronic kidney disease & $6265(4.0)$ \\
\hline Syncope & $8681(5.6)$ \\
\hline Hypertension & $61898(39.7)$ \\
\hline Sick sinus node (\%) & $1381(0.9)$ \\
\hline AV block grade 2 (\%) & $303(0.2)$ \\
\hline AV block grade 1 (\%) & $221(0.1)$ \\
\hline Bradycardia, unspecified (\%) & $1133(0.7)$ \\
\hline Procedures & \\
\hline PCI & $4776(3.1)$ \\
\hline CABG & $2335(1.5)$ \\
\hline Pharmacotherapy & \\
\hline Loop diuretics & $30560(19.6)$ \\
\hline Non-loop diuretics & $47638(30.6)$ \\
\hline RAS-inhibitors & $47045(30.2)$ \\
\hline Betablocker & $39768(25.5)$ \\
\hline CCBs & $34715(22.3)$ \\
\hline ASA & $52198(33.5)$ \\
\hline Autom
\end{tabular}

Autoimmune disorders are systemic lupus erythematosus, rheumatoid arthritis and scleroderma.

ASA, acetylsalicylic acid; AV, atrioventricular; CABG, coronary artery bypass graft; CCBs, calcium channel blockers; PCI, percutaneous coronary intervention; RAS-inhibitors, reninangiotensin inhibitors.

included prior syncope (1.92 (1.79 to 2.06)), valvular AF (1.39 (1.19 to 1.63$)$ ), hypertension (1.31 (1.25 to 1.37$)$ ), IHD (1.19 (1.13 to 1.26$)$ ), male sex (1.19 (1.13 to 1.24$)$ ) and DM (1.17 (1.09 to 1.25)) (table 2).

In the sensitivity analysis excluding CRT implantation as an outcome, the same risk factors were significantly associated with a higher rate of PPM although the rate of PPM decreased in patients with HF and age $\leq 60$ years to an HR of 1.87 (1.50 to 2.33).

Of the 8348 patients receiving a PPM, of those receiving a pacemaker, the majority were dual chamber $(48.0 \%)$ and single chamber ventricular $(30.5 \%), 44.0 \%$ of patients had a diagnosis of SSS, $19.6 \%$ had a diagnosis of third-degree AV block and $14.0 \%$ had a diagnosis of unspecified bradycardia (online supplementary table 2). In those receiving a PPM, treatment with betablockers 


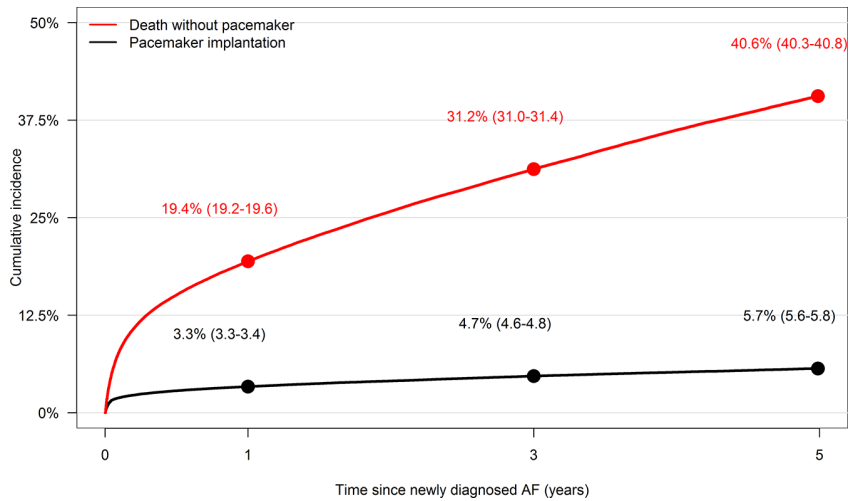

Figure 2 Cumulative incidence of permanent pacemaker and all-cause mortality for 5 years follow-up time in years since admission or outpatient date for newly diagnosed atrial fibrillation (AF).

were the most common $(39.9 \%)$ followed by digoxin $(16.1 \%)$, verapamil or diltiazem $(5.1 \%)$, amiodarone $(3.9 \%)$ and flecainide or propafenone $(1.0 \%)$. AV node ablations were rare $(0.1 \%)$.

\section{Risk score}

During the 3 months of follow-up after discharge for $\mathrm{AF}$ or first outpatient visit for $\mathrm{AF}, 2148$ patients received a PPM. The cumulative incidence (95\% CI) of PPM showed a steady increase from 0 to 3 months reaching $1.45 \%$ (1.38 to 1.51) (online supplementary figure 1).

In the 3-month prediction model, 148586 patients were included excluding 7300 patients that either died or received a PPM during initial hospitalisation (online supplementary table 3) and divided into a learning $(n=118869)$ and a validation cohort $(n=29717)$. The logistic model estimated using the learning cohort resulted in risk points given to each risk factor ranging

\begin{tabular}{|c|c|c|c|c|}
\hline Risk factors & & ts $[95 \%$ & & OR $[95 \% \mathrm{Cl}]$ \\
\hline Sex (male) & 1 & {$[0 ; 2]$} & $\vdots$ & $1.14[1.04,1.26]$ \\
\hline Hypertension & 3 & {$[2 ; 4]$} & int & $1.30[1.18,1.44]$ \\
\hline Valvular AF & 2 & {$[-1 ; 6]$} & $\vdots$ & $1.24[0.87,1.79]$ \\
\hline Diabetes & 1 & {$[0 ; 3]$} & 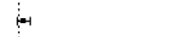 & $1.12[0.96,1.31]$ \\
\hline $\mathrm{IHD}$ & 2 & {$[0 ; 3]$} & tom & $1.17[1.04,1.30]$ \\
\hline Syncope & 9 & {$[7 ; 10]$} & $F-1$ & $2.35[2.04,2.71]$ \\
\hline $\mathrm{CHD}$ & 8 & {$[0 ; 16]$} & 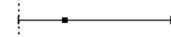 & $2.25[0.99,5.08]$ \\
\hline Age, if no Heart $\mathrm{Fa}$ & ailure & & & \\
\hline $61-70$ & 8 & {$[5 ; 10]$} & $\longmapsto$ & $2.20[1.72,2.82]$ \\
\hline $71-80$ & 13 & {$[10 ; 15]$} & $\longmapsto$ & $3.59[2.85,4.53]$ \\
\hline$>80$ & 14 & {$[12 ; 17]$} & $\longmapsto$ & $4.14[3.28,5.22]$ \\
\hline Age, if Heart Failur & & & & \\
\hline$<=60$ & 6 & {$[1 ; 11]$} & 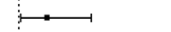 & $1.77[1.06,2.95]$ \\
\hline $61-70$ & 10 & {$[6 ; 13]$} & $\longmapsto$ & $2.66[1.86,3.80]$ \\
\hline $71-80$ & 13 & {$[10 ; 16]$} & $\longmapsto$ & $3.60[2.70,4.81]$ \\
\hline$>80$ & 11 & {$[8 ; 14]$} & $\longmapsto$ & $2.99[2.26,3.97]$ \\
\hline & & & $T$ & \\
\hline & & & 4 & \\
\hline
\end{tabular}

Figure 3 Forest plot. OR and corresponding risk points estimated from the logistic model which models the 3-month risk of PPM given all the risk factors. The model includes an interaction between age and heart failure. Summing the points corresponding to each risk factor present defines the risk score. $\mathrm{AF}$, atrial fibrillation; $\mathrm{CHD}$, congenital heart disease; IHD, ischaemic heart disease.
Table 2 Cause-specific Cox model for pacemaker and death

\begin{tabular}{|c|c|c|}
\hline Variable & $\begin{array}{l}\text { Adjusted HR for } \\
\text { pacemaker }(95 \% \mathrm{Cl})\end{array}$ & $\begin{array}{l}\text { Adjusted HR for } \\
\text { death }(95 \% \mathrm{Cl})\end{array}$ \\
\hline Sex (male) & 1.19 (1.13 to 1.24$)$ & 1.11 (1.09 to 1.13$)$ \\
\hline \multicolumn{3}{|c|}{ Interaction: heart failure and age $(\mathrm{p}<0.001)$} \\
\hline $\begin{array}{l}\text { Age } \leq 60 \text { years, no } \\
\text { heart failure }\end{array}$ & Ref & Ref \\
\hline $\begin{array}{l}\text { Age } 61-70 \text { years, } \\
\text { no heart failure }\end{array}$ & 2.26 (2.03 to 2.51$)$ & 2.49 (2.36 to 2.63$)$ \\
\hline $\begin{array}{l}\text { Age } 71-80 \text { years, } \\
\text { no heart failure }\end{array}$ & 3.29 (2.98 to 3.64$)$ & 5.06 (4.82 to 5.32 ) \\
\hline $\begin{array}{l}\text { Age }>80 \text { years, no } \\
\text { heart failure }\end{array}$ & 4.17 (3.77 to 4.61$)$ & 11.69 (11.14 to 12.27$)$ \\
\hline $\begin{array}{l}\text { Age } \leq 60 \text { years, if } \\
\text { heart failure }\end{array}$ & 2.34 (1.92 to 2.85$)$ & 2.44 (2.20 to 2.70$)$ \\
\hline $\begin{array}{l}\text { Age } 61-70 \text { years, } \\
\text { if heart failure }\end{array}$ & 2.68 (2.29 to 3.13$)$ & 4.71 (4.39 to 5.04$)$ \\
\hline $\begin{array}{l}\text { Age } 71-80 \text { years, } \\
\text { if heart failure }\end{array}$ & 3.84 (3.39 to 4.35$)$ & 8.31 (7.85 to 8.78$)$ \\
\hline $\begin{array}{l}\text { Age }>80 \text { years, if } \\
\text { heart failure }\end{array}$ & 3.51 (3.10 to 3.97 ) & 16.59 (15.77 to 17.46$)$ \\
\hline \multicolumn{3}{|l|}{ Comorbidities } \\
\hline $\begin{array}{l}\text { Autoimmune } \\
\text { disorder }\end{array}$ & 0.86 (0.69 to 1.08$)$ & 1.35 (1.26 to 1.45$)$ \\
\hline $\begin{array}{l}\text { Chronic kidney } \\
\text { disease }\end{array}$ & 1.01 (0.91 to 1.13$)$ & 1.93 (1.87 to 2.00$)$ \\
\hline Diabetes mellitus & 1.17 (1.09 to 1.25$)$ & 1.25 (1.22 to 1.29$)$ \\
\hline $\begin{array}{l}\text { Ischaemic heart } \\
\text { disease }\end{array}$ & 1.19 (1.13 to 1.26$)$ & 1.05 (1.03 to 1.07$)$ \\
\hline Hypertension & 1.31 (1.25 to 1.37$)$ & 1.01 (0.99 to 1.02) \\
\hline Valvular AF & 1.39 (1.19 to 1.63$)$ & 0.71 (0.65 to 0.78$)$ \\
\hline Syncope & 1.92 (1.79 to 2.06$)$ & 1.02 (0.98 to 1.05$)$ \\
\hline $\begin{array}{l}\text { Congenital heart } \\
\text { disease }\end{array}$ & 2.42 (1.74 to 3.38$)$ & $0.91(0.72$ to 1.16$)$ \\
\hline \multicolumn{3}{|l|}{ Procedures } \\
\hline CABG & $0.86(0.73$ to 1.01$)$ & $0.60(0.55$ to 0.65$)$ \\
\hline $\mathrm{PCl}$ & 1.09 (0.97 to 1.22$)$ & $0.72(0.68$ to 0.76$)$ \\
\hline
\end{tabular}

The HRs are estimated using 5 years of follow-up for the rate of pacemaker and all-cause mortality.

$\mathrm{AF}$, atrial fibrillation; CABG, coronary artery bypass graft; $\mathrm{PCI}$, percutaneous coronary intervention.

from 1 to 14 , with age contributing up to 14 points (age $>80$, if no HF) (figure 3). The patient risk score was derived by summing the points corresponding to each risk factor (online supplementary table 4).

The validation cohort showed increasing risk of PPM with increasing risk point $(95 \% \mathrm{CI})$, from $0.4 \%$ (0.2 to 0.8 ) at 1 point to $2.6 \%$ (1.9 to 3.6 ) at 18 points (figure 4 ). See online supplementary figure 2 for similar results obtained from the full cohort. Discrimination performances by age group are provided in online supplementary figure 3 . The AUC estimated $(95 \% \mathrm{CI})$ on the 


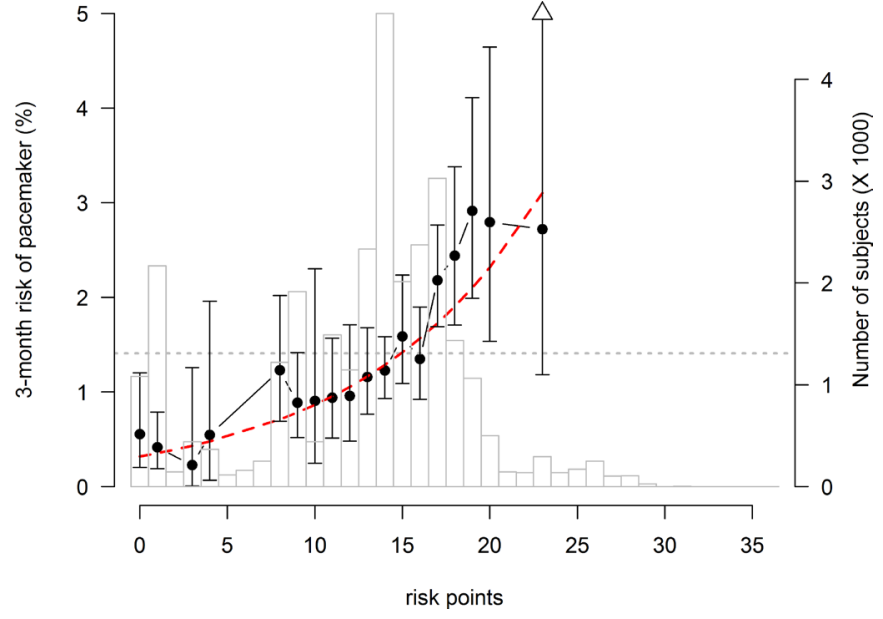

Figure 4 Distribution of risk points and 3-month risk of permanent pacemaker in the validation cohort. Displayed are the estimated risk (dots, left axis) with 95\% Cls and numbers of subjects per risk points (bars, right axis). The dashed line displays the risk which is predicted by the logistic model. The dotted line displays the estimate of the marginal risk. A triangle indicates that the $\mathrm{Cl}$ is truncated. Data not shown when less than 200 subjects are observed with the corresponding number of points.

validation cohort was 62.9 (60.3 to 65.5) (figure 5), which was close to the 'apparent' AUC estimated on the learning cohort 64.0 (62.9 to 65.1). The AUC of the risk score performed significantly better than the AUC with age alone $(p<0.001)$. Online supplementary figure 4 shows the AUC for 5-year prediction. It also shows that the risk score performed significantly better than age alone for 5 -year prediction $(\mathrm{p}<0.001)$. The estimated true positive rates, false positive rates, positive predictive values and negative predictive values for each cut-off are in online supplementary table 5 . At 20 points, the positive predictive value was $2.5 \%$ (1.8 to 3.5 ) and negative predictive value was $98.6 \%$ (98.5 to 98.8 ).

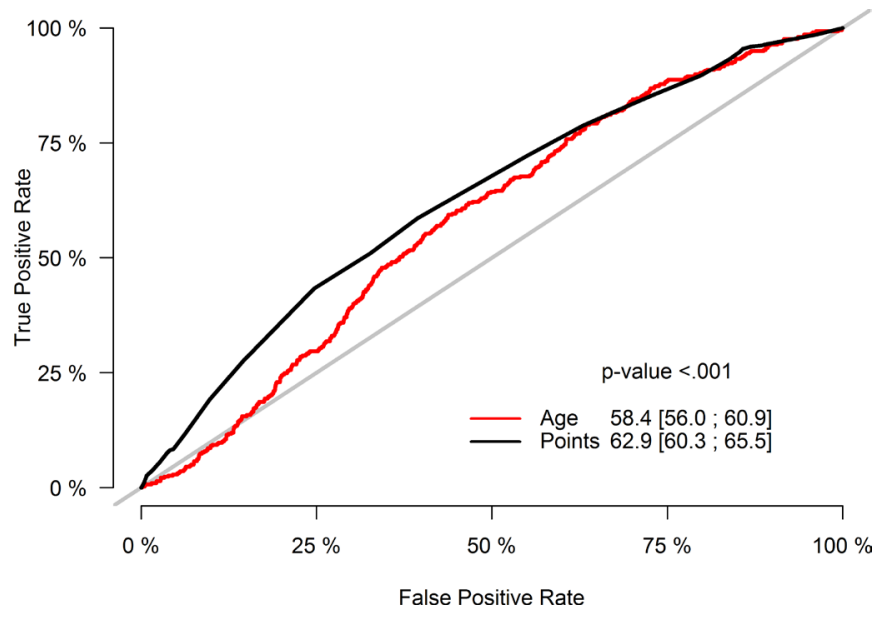

Figure 5 Receiver operator characteristics curve estimated from the validation cohort for 3 months prediction. Area under the curve with $95 \% \mathrm{Cl}$ for the risk score and age alone.

\section{DISCUSSION}

\section{Main findings}

To our knowledge, this is the largest cohort study to determine important risk factors for PPM and the first study to produce a 3-month risk score predicting PPM risk in patients with newly diagnosed AF. Significant covariates were identified as risk factors of PPM: age $>60$ years, CHD, age $\leq 60$ years and $\mathrm{HF}$, prior syncope, valvular $\mathrm{AF}$, hypertension, IHD, male sex and DM. A risk score was produced and internally validated to predict PPM implantation in a 3-months follow-up.

Multiple treatment options are available to treat heart rate and rhythm in AF patients: pulmonary vein ablation, antiarrhythmic medication or rate control medication. For some patients, rate or rhythm control may be insufficient and selected patients may undergo AV node ablation with permanent pacing. ${ }^{13}$ In our study, AV node ablation and CRT implantation was rare, most patients receiving a PPM received a dual chamber pacemaker and single ventricular pacemaker, and most of the patients had a bradycardia diagnosis, thus we think the majority of PPMs was placed to treat bradycardia. A PPM implantation relies on the decision making by the treating physician considering many factors influencing PPM risk; our findings suggest that certain clinical risk factors affect the need of pacing in newly diagnosed AF patients.

\section{Risk factors}

Age is a well-known risk factor of bradycardia ${ }^{14}$ and older patients with AF might be more susceptible for bradyarrhythmic side-effects of AV-blocking medication ${ }^{15}$ potentially leading to increased risk of PPM. Another important risk factor of PPM was CHD. Patients with AF and concomitant CHD are a heterogenetic group that have often had heart surgery that could lead to bradycardias. However, CHD in itself could also increase the risk. Studies have shown that types of CHD procedures are associated with a different prevalence of SSS and AV block ${ }^{16}$ suggesting that these patients are prone to bradycardias.

HF combined with age $\leq 60$ years was an important risk factor. One study $(n=362)$ investigated risk factors of PPM placed for symptomatic bradycardia in AF patients; the study found an increased risk with HF (OR: 2.72 (95\% CI: 1.47 to 5.01 ) ) and permanent AF (OR: 2.99 (1.61 to $5.57)) .{ }^{17}$ Our study findings support the association with $\mathrm{HF}$, although we found the association of PPM with HF was primarily in those at younger age. The association of PPM with HF in the younger AF cohort may partially be explained by the aetiology of the HF, which is more likely to be structural and pacing can improve symptoms in these patients. Prior diagnosis of syncope was highly associated with PPM. Syncope can be a symptom of underlying undiagnosed malignant arrhythmia and hospitalisation for syncope often leads to vigorous work-up in the search for arrhythmias, which in some cases results in PPM. ${ }^{18}$ Our study indicates that patients with valvular AF have an increased rate of PPM. Valvular surgery, especially aortic valve replacement, has, in previous studies, shown 
to be associated with PPM. ${ }^{19}$ Hypertension, IHD and DM were all associated with PPM implantation. Prior studies present similar findings and propose a mechanism related to progression of cardiac ischaemia, scar-related conduction disease and microangiopathy. ${ }^{20}{ }^{21}$ Male sex was also associated with PPM implantation. One study showed that females are less likely to receive a PPM, likely due to their older age at disease presentation and decreased body size which potentially increase the risk of procedural complications. ${ }^{22}$ It is unclear from our study whether our findings are a sign of under treatment in females. We found no association between PPM and autoimmune disorders or chronic kidney disease.

\section{Risk score}

Based on the risk score, one can classify newly diagnosed AF patients' individual as being at 'high' or 'low' risk of PPM within 3 months using several cutoffs. Our results provide detailed estimates of the discriminative performance that one can expect when using the different cutoffs. Overall, the risk score discriminates significantly better than age alone, both for 3 months and 5 years. It combines nine covariates, by assigning points ranging from 1 to 14 to each of them, with age contributing up to 14 points (age $>80$, if no HF) (figure 3 ). We chose a model with better predictive accuracy (3-month model) over long-term prediction with poor predictive accuracy (5-year model). The discriminative performances that we have estimated already provide estimates of the impact that defining such guidelines could have, in terms of true and false selection of subjects at 'high risk'. Currently, the discriminative abilities of the risk factor in particular the true positive prediction was modest and therefore future research is warranted to refine the risk score by adding new important predictors such as left bundle branch block, type of AF and heart rate which could possibly improve discriminative abilities. The high negative predictive value of the risk score may have clinical use as it shows that the score can help to identify at very low risk of PPM. Most importantly, studies are needed to externally validate the risk score. Receiving a pacemaker is a valid concern for patients. This risk score could help patients and healthcare providers to estimate the risk of undergoing PPM procedure. The score might be most useful for informing patients of age above 71 years as it seems that the risk score has the best discrimination ability in that age group (online supplementary figure S3).

\section{Limitations}

This observational study has some important limitations: the non-availability of frequency of AF episodes and AF type (paroxysmal, persistent or permanent), time of $\mathrm{AF}$ diagnosis and pacemaker-dependency. We were unable to distinguish between $\mathrm{AF}$ and atrial flutter; however, it is estimated that around $95 \%$ of the diagnosis $\mathrm{I} 48$ is $\mathrm{AF}$ and not atrial flutter. ${ }^{23}$ Too few patients had CHD at baseline to make subtypes based on surgical repair. No data were available on individual PPM indication. PPM implantations were rare and the high-risk patients found are relative to those with low risk. We mainly present results for the 3-months outcome as the information used to define the risk points are not informative enough to make clinically relevant 5 -year risk predictions, as suggested by the low AUC of the ROC curve at 5 years and the competing risk of death was high during the 5 -year follow-up. The risk score should be used with caution before external validation has been performed. It is likely that the sensitivity of the diagnosis for bradycardia may not be very high, that is, patients with bradycardia do not always get the diagnosis registered. Therefore, we did not include it in the models. Our use of the date of newly diagnosed AF only did not allow us to assess for the potential bradycardia risk of rate-lowering or antiarrhythmic drugs prescribed after the $\mathrm{AF}$ diagnosis, aside from betablockers and calcium channel blockers which was categorised in the predictor 'hypertension'. Being a registry study, there are no clinical data on blood pressure, laboratory findings, smoking status, weight or ECG characteristics such as information on conduction abnormality.

\section{CONCLUSION}

Overall, the 5-year risk for PPM in newly diagnosed AF patients was $5 \%$. We identified nine risk factors of PPM: age above 60 years, CHD, age $\leq 60$ years with $\mathrm{HF}$, prior syncope, valvular AF, hypertension, IHD, male sex and DM. A risk score was produced to predict the absolute risk of PPM during a 3-months follow-up after discharge or outpatient visit for AF diagnosis. The clinical utility of the novel risk score needs further investigation.

\section{Twitter Frederik Dalgaard @F_dalgaard}

Contributors FD, MHR, GG, JLP and PB contributed to the study concept and design; FD and PB conducted the data analysis; FD drafted the manuscript; JLP, TBL, CTP, GG and MHR critically reviewed all drafts of the manuscript.

Funding This work was supported by the Danish Heart Foundation (grant number: 16-R107-A6776-22972 and 17-R115-A7443-22062); and FUKAP, research fund of the Department of Cardiology, Herlev and Gentofte Hospital.

Competing interests The authors declared the following potential conflicts of interest with respect to the research, authorship and/or publication of this article: Gunnar Gislason has ownership of stocks in Novo Nordisk Pharmaceuticals and reports research grants from AstraZeneca, Pfizer, Bristol Myers Squibb, Boerhringer Ingelheim and Bayer. Christian Torp-Pedersen declares grants for studies from Bayer. Other authors have no conflict of interest to declare.

\section{Patient consent for publication Not required.}

Ethics approval In Denmark, retrospective register studies do not require approval from the ethics committees. The Danish Data Protection Agency approved this study (Ref no 2007-58-015 I-Suite nr: 02720, GEH-2014-012). Data were made available in an anonymised format such that specific individuals could not be identified.

Provenance and peer review Not commissioned; externally peer reviewed.

Data availability statement Data may be obtained from a third party and are not publicly available. Due to restrictions related to Danish law and protecting patient privacy, the combined set of data as used in this study can only be made available through a trusted third party, Statistics Denmark. This state organisation holds the data used for this study. Any request on data access should be addressed to Statistics Denmark https://www.dst.dk/en.aspx\#. 
Open access This is an open access article distributed in accordance with the Creative Commons Attribution Non Commercial (CC BY-NC 4.0) license, which permits others to distribute, remix, adapt, build upon this work non-commercially, and license their derivative works on different terms, provided the original work is properly cited, appropriate credit is given, any changes made indicated, and the use is non-commercial. See: http://creativecommons.org/licenses/by-nc/4.0/.

ORCID iD

Frederik Dalgaard http://orcid.org/0000-0002-7287-4191

\section{REFERENCES}

1 Steinbach M, Douchet M-P, Bakouboula B, et al. Outcome of patients aged over 75 years who received a pacemaker to treat sinus node dysfunction. Arch Cardiovasc Dis 2011;104:89-96.

2 Li H, Lakkireddy D, Korlakunta H, et al. Pacemaker utilization during permanent atrial fibrillation in patients who received pacemaker implantation for sinus node dysfunction. Am J Cardiol 2005;96:942-5.

3 Ruwald MH, Hansen ML, Lamberts M, et al. The relation between age, sex, comorbidity, and pharmacotherapy and the risk of syncope: a Danish nationwide study. Europace 2012;14:1506-14.

4 Dalgaard F, Pallisgaard JL, Numé A-K, et al. Rate or rhythm contro in older atrial fibrillation patients: risk of fall-related injuries and syncope. J Am Geriatr Soc 2019;67:2023-30.

5 Hjortshøj S, Riahi S, Nielsen JC, et al. Does atrial pacing lead to atrial fibrillation in patients with sick sinus syndrome? insights from the DANPACE trial. Europace 2014;16:241-5.

6 Essebag V, Hadjis T, Platt RW, et al. Amiodarone and the risk of bradyarrhythmia requiring permanent pacemaker in elderly patients with atrial fibrillation and prior myocardial infarction. J Am Coll Cardiol 2003;41:249-54.

7 Wyse DG, Waldo AL, DiMarco JP, et al. A comparison of rate control and rhythm control in patients with atrial fibrillation. N Engl J Med 2002;347:1825-33.

8 Dalgaard F, Pallisgaard JL, Lindhardt TB, et al. Rate and rhythm therapy in patients with atrial fibrillation and the risk of pacing and bradyarrhythmia. Heart Rhythm 2019;16:1348-56.

9 Dalgaard F, Ruwald MH, Lindhardt TB, et al. Patients with atrial fibrillation and permanent pacemaker: temporal changes in patient characteristics and pharmacotherapy. PLoS One 2018;13:e0195175.

10 Adelborg K, Sundbøll J, Munch T, et al. Positive predictive value of cardiac examination, procedure and surgery codes in the Danish national patient registry: a population-based validation study. BMJ Open 2016;6:e012817

11 DeLong ER, DeLong DM, Clarke-Pearson DL. Comparing the areas under two or more correlated receiver operating characteristic curves: a nonparametric approach. Biometrics 1988;44:837-45.

12 Blanche P, Dartigues J-F, Jacqmin-Gadda H. Estimating and comparing time-dependent areas under receiver operating characteristic curves for censored event times with competing risks. Stat Med 2013:32:5381-97.

13 Kirchhof P, Benussi S, Kotecha D, et al. 2016 ESC guidelines for the management of atrial fibrillation developed in collaboration with EACTS. Eur Heart J 2016;37:2893-962.

14 Choudhury M, Boyett MR, Morris GM. Biology of the sinus node and its disease. Arrhythm Electrophysiol Rev 2015;4:28-34.

15 Maisel WH, Kuntz KM, Reimold SC, et al. Risk of initiating antiarrhythmic drug therapy for atrial fibrillation in patients admitted to a university hospital. Ann Intern Med 1997;127:281-4.

16 Khairy P, Aboulhosn J, Gurvitz MZ, et al. Arrhythmia burden in adults with surgically repaired tetralogy of Fallot: a multi-institutional study. Circulation 2010;122:868-75

17 Barrett TW, Abraham RL, Jenkins CA, et al. Risk factors for bradycardia requiring pacemaker implantation in patients with atria fibrillation. Am J Cardiol 2012;110:1315-21.

18 Palmisano P, Accogli M, Zaccaria M, et al. Predictive factors for pacemaker implantation in patients receiving an implantable loop recorder for syncope remained unexplained after an extensive cardiac and neurological workup. Int J Cardiol 2013;168:3450-7.

19 Al-Ghamdi B, Mallawi Y, Shafquat A, et al. Predictors of permanent pacemaker implantation after coronary artery bypass grafting and valve surgery in adult patients in current surgical era. Cardiol Res 2016;7:123-9.

20 Hsueh CW, Lee WL, Chen YT, et al. The incidence of coronary artery disease in patients with symptomatic bradyarrhythmias. Jpn Heart $J$ 2001;42:417-23

21 Lear JT, Lawrence IG, Burden AC. Prevalence of diabetes in elderly patients requiring permanent cardiac pacemaker insertion. Acta Diabetol 1996;33:169-70.

22 Nowak B, Misselwitz B, Erdogan A, et al. Do gender differences exist in pacemaker implantation?--results of an obligatory external quality control program. Europace 2010;12:210-5.

23 Rix TA, Riahi S, Overvad K, et al. Validity of the diagnoses atrial fibrillation and atrial flutter in a Danish patient registry. Scand Cardiovasc J 2012;46:149-53. 